Male Bisexual Arousal: A Matter of Curiosity?

\author{
Gerulf Rieger \\ Cornell University \\ Allen M. Rosenthal \\ Northwestern University \\ Brian M. Cash \\ Cornell University \\ Joan A. W. Linsenmeier, and J. Michael Bailey \\ Northwestern University \\ Ritch C. Savin-Williams \\ Cornell University \\ Author Note
}

Gerulf Rieger, Department of Human Development, Cornell University. Gerulf

Rieger is now in the Department of Psychology, University of Essex; Allen M. Rosenthal, Department of Psychology, Northwestern University; Brian M. Cash, Department of Human Development, Cornell University; Joan A. W. Linsenmeier, Department of Psychology, Northwestern University; J. Michael Bailey, Department of Psychology, Northwestern University; Ritch C. Savin-Williams, Department of Human Development, Cornell University.

This research was supported by the American Institute of Bisexuality and the United States Department of Agriculture's Federal Formula Funds.

We thank James Jones-Rounds from the Human Development EEG and Psychophysiology Laboratory at Cornell and Sanjay Dharmavaram for technical assistance.

Correspondence concerning this article should be addressed to Gerulf Rieger, Department of Psychology, University of Essex, Colchester C04 3SQ, UK. Email: gerulf@essex.ac.uk 


\begin{abstract}
Conflicting evidence exists regarding whether bisexual-identified men are sexually aroused to both men and women. We hypothesized that a distinct characteristic, level of curiosity about sexually diverse acts, distinguishes bisexual-identified men with and without bisexual arousal. Study 1 assessed men's $(N=277)$ sexual arousal via pupil dilation to male and female sexual stimuli. Bisexual men were, on average, higher in their sexual curiosity than other men. Despite this general difference, only bisexual-identified men with elevated sexual curiosity showed bisexual arousal. Those lower in curiosity had responses resembling those of homosexual men. Study 2 assessed men's $(N=72)$ sexual arousal via genital responses and replicated findings of Study 1. Study 3 provided information on the validity on our measure of sexual curiosity by relating it to general curiosity and sexual sensation seeking $(N=83)$. Based on their sexual arousal and personality, at least two groups of men identify as bisexual.

Keywords: sexual orientation, personality, bisexuality, pupil dilation, genital arousal
\end{abstract}




\section{Male Bisexual Arousal: A Matter of Curiosity?}

Previous research investigated several links between personality and aspects of sexuality, for example, individual differences in sex drive (Lippa, 2006), risky sexual behavior (Zietsch, Verweij, Bailey, Wright, \& Martin, 2010), and sociosexuality (Quist et al., 2012). Little research, however, has been conducted regarding the relationship between personality and sexual orientation; one thoroughly studied exception is masculinity-femininity (Lippa, 2008). We examined the possibility that a different personality trait, level of curiosity towards sexually diverse acts, is linked to a specific sexual orientation, male bisexuality. Individuals differ in their curiosity about a wide range of sexual attitudes - including their interest in seeing others naked, observing someone else having sex, watching pornographic movies, or taking part in sex orgies (Eysenck, 1970, 1973, 1976; Heaven, Fitzpatrick, Craig, Kelly, \& Sebar, 2000). Based on the terminology used by Eysenck, we refer to this characteristic as sexual curiosity. With the present studies, we suggest a mechanism that accounts for seemingly contradictory previous findings: Level of sexual curiosity explains why some bisexual-identified men show bisexual arousal patterns whereas others do not.

\section{Male Bisexual Identity and Sexual Arousal}

People adopt a bisexual identity for many reasons, including past or current sexual attractions or sexual behaviors, the capacity to fall in love with men and women, discomfort with being labeled "straight," "gay," or "lesbian," or out of loyalty towards a

nonheterosexual community (Fox, 2003; Rust, 2001). Perhaps because of this diversity, men and women with bisexual identities remain poorly understood; moreover, at times they are even dismissed as misrepresenting their true sexual orientation (Dodge et al., 
2012; Rust, 2002). This latter state stems, in part, from the extended debate about whether bisexual-identified men show sexual arousal patterns consistent with their identity, similar to heterosexual and homosexual men (Bailey, 2009). Some research suggests that bisexual-identified men are sexually aroused to both men and women, as measured by their genital responses or pupillary responses (Rieger \& Savin-Williams, 2012; Rosenthal, Sylva, Safron, \& Bailey, 2011). However, other research suggests that most bisexual-identified men are similar to homosexual men in exhibiting almost exclusive sexual arousal to men (Rieger, Chivers, \& Bailey, 2005; Tollison, Adams, \& Tollison, 1979).

A different line of research suggests that bisexual men, more so than heterosexual or homosexual men, are sexually aroused if presented with bisexual stimuli (i.e., sexual stimuli depicting two males and one female) and thus show bisexual responses (Cerny \& Janssen, 2011; Rosenthal, Sylva, Safron, \& Bailey, 2012). Yet, given the nature of these stimuli it is difficult to tell whether it was sexual arousal to both sexes, or sexual arousal towards one of the presented sexes, that contributed to this finding. In fact, when responses of the same men to stimuli depicting only men or stimuli depicting only women were investigated, bisexual-identified men from one dataset showed bisexual arousal patterns (Rosenthal et al., 2011), whereas bisexual-identified men from the other dataset had arousal patterns similar to homosexual men (Bailey, Rieger, \& Rosenthal, 2011). Hence, with respect to their sexual arousal towards men or women, at least two groups of bisexual-identified men appear to exist. We refer hereafter to bisexualidentified men as bisexual regardless of their sexual arousal patterns.

\section{Male Bisexual Identity and Sexual Curiosity}


Eysenck (1976) proposed that genetic and physiological influences account for individual differences in a variety of personality characteristics, including a range of sexual attitudes and desires. One particular sexual attitude is the aforementioned trait, sexual curiosity, that includes, for example, elevated interests in watching erotic images or movies or participating in orgies (Eysenck, 1970, 1973). Sexual curiosity might be linked to a bisexual identity.

Stereotypes of bisexual people include the belief that they are more sexually experimental and promiscuous than heterosexual or homosexual people, more interested in short-term mating strategies, and more open to new experiences (Israel \& Mohr, 2004; Zivony, 2013). Some bisexual men do, in fact, have stronger sexual attractions to and fantasies about both men and women, and are more sexually adventurous than most men (Weinrich \& Klein, 2002). Among men with bisexual behaviors, several groups were identified and two of these groups had larger numbers of either male or female sex partners than other men (Taywaditep \& Stokes, 1998). For bisexual men, unlike for both heterosexual men and homosexual men, those with a higher sex drive are likely to be more sexually attracted to both men and women (Lippa, 2007). In addition, men with bisexual experiences have, on average, a genetic make-up associated with higher levels of sensation seeking (Hamer \& Copeland, 1994).

In one small sample of 30 men, bisexual men reported, on average, more sexual curiosity than either heterosexual or homosexual men, $p=.01, \beta=-.47$ (Rieger, Stief, Puts, \& Savin-Williams, 2012). However, as reflected in several studies cited above, a diverse range of people identify as bisexual (Lewis, Derlega, Brown, Rose, \& Henson, 2009). Even if, on average, they were more sexually curious than other groups, this 
would not imply that all bisexual men are high in sexual curiosity. Perhaps, then, variations in sexual curiosity explain why some bisexual men show bisexual arousal patterns whereas others do not.

\section{Male Bisexual Identity, Sexual Curiosity, and Sexual Arousal}

Degree of sexual curiosity could differentiate bisexual men's sexual arousal patterns in two plausible ways. First, only bisexual men with elevated levels of sexual curiosity might show bisexual arousal. Eysenck (1976) suggested that genetic and physiological influences account for differences in personality characteristics, and that these characteristics relate to a variety of sexual attitudes, interests, and behaviors. Recent behavioral-genetic models confirm a common genetic factor for certain personality characteristics and risky sexual attitudes (Zietsch et al., 2010). Other analyses suggest genetic underpinnings for both novelty-seeking characteristics (Munafò, Yalcin, WillisOwen, \& Flint, 2008) and a range of sexual attitudes and preferences (Ben Zion et al., 2006; Garcia et al., 2010; Halpern, Kaestle, Guo, \& Hallfors, 2007).

In theory, a common factor, such as genetic influences, can be applicable to specific combinations of personality and sexuality. In line with Eysenck's (1976) broad theory, a genetic predisposition could account for increased sexual curiosity and increased sexual attraction and arousal to both men and women. Hence, those bisexual men with increased sexual interests might be more sexually aroused to both sexes. Because sexual arousal likely affects the formation of most male sexual identities (Bailey, 2009), these predispositions could form the basis for some men's bisexual identification. Given this proposal, only bisexual men with high levels of sexual curiosity will be sexually aroused to both men and women. In contrast, bisexual men who do not have 
elevated levels of sexual curiosity would be primarily sexually aroused to one sex, similar to most men (Bailey, 2009).

Second, and alternatively, sexual curiosity might distinguish between bisexual men with and without bisexual arousal patterns in an opposite manner than the one described above. That is, some men might show substantial bisexual arousal although their sexual curiosity is not elevated, and this bisexual arousal could form the basis for a bisexual identity. Other bisexual men, though, might show elevated sexual curiosity but not substantial bisexual arousal. Because of low inhibition to a variety of sexual stimuli, or high excitation to them, or a combination of both (Bancroft, Graham, Janssen, \& Sanders, 2009; Janssen, Vorst, Finn, \& Bancroft, 2002), elevated sexual curiosity in the latter group could override their predominant preference for one sex. Consequently, due to their high levels of sexual curiosity, these men might seek sexual experiences with both men and women, even if they prefer one to the other, and subsequently identify as bisexual. In sum, sexual curiosity and bisexual arousal could interplay in two possible ways - they are either linked to each other or expressed independently of each other. In either case, this interplay between personality characteristics and sexual arousal patterns might distinguish between those bisexual men who are sexually aroused to both sexes and those who are not.

\section{Measurement of Sexual Arousal}

The first of the current studies used pupil dilation as an index of sexual arousal. Pupil dilation to stimuli indicates activation of the autonomic nervous system (Bradley, Miccoli, Escrig, \& Lang, 2008) that is associated with many automatic processes such as perspiration, digestion, blood pressure, and heart rate (ten Donkelaar, Němcová, 
Lammens, Overeem, \& Keyser, 2011). Other research suggests that pupil dilation reflects attention that is likely not in the conscious control of participants (Heaver \& Hutton, 2011). For these reasons, pupil dilation has been used as an indicator of automatic responses, including responses reflecting sexual arousal (Goldinger \& Papesh, 2012; Laeng, Sirois, \& Gredebäck, 2012). Pupils dilate more to sexual stimuli depicting an individual's preferred sex than to stimuli of the other sex or to non-sexual stimuli (Hess \& Polt, 1960; Hess, Seltzer, \& Shlien, 1965; Rieger \& Savin-Williams, 2012). In fact, dilation to sexually preferred stimuli appears to be the strongest pupillary response elicited by stimuli (Laeng et al., 2012). In addition, degree of pupil dilation corresponds with time spent viewing these stimuli, self-reported sexual attraction to stimuli, and selfreported sexual orientation (Hess et al., 1965; Rieger \& Savin-Williams, 2012). These findings point to the utility of this measure for the present research.

The second study assessed men's genital responses to sexual stimuli, an established indicator of their sexual attraction and arousal. This is achieved by assessing changes in penile circumference or volume with gauges worn by participants (Janssen, 2002, 2011). Genital arousal is a strong indicator of male sexual orientation in the sense that heterosexual men exhibit almost exclusive genital arousal to women but not to men, and homosexual men exhibit almost exclusive genital arousal to men but not to women (Chivers, Seto, \& Blanchard, 2007; Freund, Langevin, Cibiri, \& Zajac, 1973; Rieger et al., 2005; Sakheim, Barlow, Beck, \& Abrahamson, 1985). Because men's genital arousal to sexual stimuli is less likely under their conscious control than their self-reported sexual attraction to these stimuli (Janssen, 2011), it is preferred to self-report by researchers who seek an automatic measure of male sexual attraction and arousal (Seto, 2004). 
Depending on a researcher's design, one or both of these measures of sexual arousal are applicable. The assessment of sexual arousal via pupil dilation is less invasive than the assessment via genital response, and likely draws a broader range of participants to a study; a benefit of genital assessment is that sexual orientation differences are stronger than those found with pupil dilation, at least for males (Rieger \& Savin-Williams, 2012). More important for the present research, however, if patterns of results were similar across these measures and with different samples, it would point to the robustness of differences in sexual arousal between different types of bisexual men.

\section{Measurement of Sexual Curiosity}

The present measure of sexual curiosity was influenced by the measure introduced by Eysenck $(1970,1973)$. However, several of the original items were modified and others added in order to create a modern version. In addition, Eysenck introduced the term sexual curiosity well before recent understanding of curiosity as a global trait emerged. Hence, it is important to establish the degree to which our measure of sexual curiosity is valid and related to the global trait. In general, curiosity can be described as an "emotional-motivational system that energizes and directs novelty-seeking behaviors, with the ultimate goal of stimulating one's interest” (Litman \& Silvia, 2006, p. 319). Recent work has measured global curiosity (Kashdan et al., 2009; Peterson \& Park, 2009) as well as those facets of the global trait reflecting the gaining of knowledge and the stimulation of the senses (Collins, Litman, \& Spielberger, 2004; Litman \& Spielberger, 2003).

If sexual curiosity is an aspect of general curiosity, then measures of the two should be related. We assessed this relationship in our third study. The exact strength of this 
relationship is difficult to predict. However, Litman and Silvia (2006, pp. 319-320) reported correlations of current measures (either for scales measuring the global trait or facets of the global trait) with other, conceptually relevant traits, as well as with previous measures of curiosity. The average correlation coefficient (based on both full and partial correlations) across all findings reported was $r=.37$ with a $95 \%$ confidence interval of .29 to .45 . Hence, if sexual curiosity relates to the general trait, the correlation will likely fall within this range.

Another trait theoretically linked to curiosity is sensation seeking: a need for novel and varied experiences and the willingness to take physical and social risks for the sake of these experiences (Hoyle, Stephenson, Palmgreen, Lorch, \& Donohew, 2002; Zuckerman, 1979). Similar to curiosity, sensation seeking directs exploratory behaviors and stimulation of the senses; unlike curiosity, sensation seeking shows a lower relationship with the need for gaining knowledge (Collins et al., 2004; Litman \& Spielberger, 2003). Still, sensation seeking may be relevant for the present research. One aspect of sensation seeking is sexual sensation seeking, or the tendency to seek novel, intense, and, at times, risky sexual experiences (Kalichman et al., 1994; Kalichman \& Rompa, 1995). Because both curiosity and sensation seeking involve novelty and stimulation, it is possible that sexual curiosity corresponds with sexual sensation seeking. Establishing this relationship will point to the convergent validity of these measures. We also explored this possibility in our final study.

\section{Overview of Studies}

Across the three studies, the following hypotheses were tested: 
Hypothesis 1. Bisexual men will, on average, report elevated levels of sexual curiosity compared with both heterosexual and homosexual men.

Hypothesis 2. Given some previous findings, bisexual men will, as a group, show sexual arousal to both sexes compared with heterosexual and homosexual men, who will be aroused primarily by one sex.

Hypothesis 3. Given other previous findings, bisexual men will, as a group, show stronger sexual arousal to men than to women, similar to homosexual men and different from heterosexual men.

In addition, the relation of sexual curiosity with sexual arousal was assessed to evaluate two hypotheses:

Hypothesis 4. Bisexual men with high levels of sexual curiosity will be sexually aroused to both men and women. Those with lower levels of sexual curiosity will show arousal to only one sex.

Hypothesis 5. Alternatively, some bisexual men will show bisexual arousal but not elevated levels of sexual curiosity, and other bisexual men will show high levels of sexual curiosity but not bisexual arousal.

Hypothesis 6. Sexual curiosity will correspond with theoretically related measures, specifically, overall curiosity, overall sensation seeking, and sexual sensation seeking.

Study 1 examined the first five hypotheses by assessing sexual arousal via pupil dilation to sexual stimuli and by linking it to self-reported sexual orientation and sexual curiosity. Study 2 further examined these relationships by measuring sexual arousal via genital response. For this purpose, Study 2 reanalyzed data of a previous study 
(Rosenthal et al., 2011), that included relevant unpublished information. Study 3 examined Hypothesis 6 by assessing the correspondence among measures.

Other hypotheses were also examined. For example, some bisexual men reported equal attractions to men and women, others reported stronger attractions to women than men, and others reported stronger attractions to men than women. Analyses yielded no significant differences between these groups; thus, for the sake of simplicity, they will not be further discussed.

\section{Study 1}

\section{Method}

Participants. Advertisements were placed on several websites of a Northeast college town, including those for dormitories, fraternities, athletic teams, and associations for sexual minorities. We also recruited from websites where men sought both men and women for sexual reasons. The latter method was previously successful in recruiting men with bisexual identities, a group less prevalent than other men (Rosenthal et al., 2011). An advertisement read, for example, "Bisexual men wanted for a study on personality and sexuality. Participation takes less than one hour and you will be compensated with \$30.”

A total of 277 recruited men indicated their sexual orientation identity on a 7-point scale, ranging from "exclusively straight" to "bisexual" to "exclusively gay." Table 1 shows the number of participants for each sexual orientation identity by age, ethnicity, and recruitment venue (sexual website or otherwise). The average age $(S D)$ was 23.29 (6.32) years. The most common ethnicity was Caucasian (66\%). Fifty-five men (20\%) were recruited through websites men visited for sexual reasons. 
There were no significant differences among sexual orientation identities in the proportion of men who were Caucasian, $\chi^{2}(6)=3.02, p=.81$. Table 1 shows that men with a range of sexual orientations towards both sexes were older than other men, $p$ $<.0001, R^{2}=.11$, and more likely recruited from sites where men seek sexual encounters, $\chi^{2}(6)=28.62, p<.0001$. These differences had little effect on results, however, as we report below.

For 165 participants other data have been previously published (Rieger \& SavinWilliams, 2012). The following results were not significantly different between this first sample and the additional 112 men (all $p$ 's $>.17$, all $\beta$ 's between -.08 and .05 ). Thus, results are based on all participants.

\section{Measures.}

Sexual orientation. Participants reported their sexual orientation identities (Table 1), sexual attractions, and sexual fantasies on Kinsey-type Scales (Kinsey, Pomeroy, \& Martin, 1948). Measures were highly correlated (all $p$ 's $<.0001$, all $r$ 's $\geq .97$ ), and thus averaged within participants. For this composite average, a score of 0 indicated an exclusively heterosexual orientation, a score of 3 a bisexual orientation with equal preferences towards men and women, and a score of 6 an exclusively homosexual orientation.

Sexual curiosity. A 10-item scale was adapted from the factors "sexual curiosity" and "sexual promiscuity" of the Inventory of Attitudes to Sex (Eysenck, 1970). Example items are "If I were invited to see a porn movie, I would accept," and "The idea of partner-swapping is exciting to me." The complete list of items is shown in the Appendix. Participants used 7-point scales to indicate agreement with items. Item reliability 
(Cronbach's $\alpha$ ) was .89 and responses were averaged within participants. For these averages, a score of 7 indicated maximum sexual curiosity.

Stimuli. Thirty-second videos of 12 male stimuli and 12 female stimuli were used for the study. Stimuli were of similar luminance; furthermore, luminance was set to equal upper and lower thresholds across stimuli by using the programs MPEG Streamclip and Final Cut Pro. Videos had similar content (i.e., a naked person in a bedroom) and depicted either a male model or female model masturbating.

In a pilot study the most attractive models were selected from a large pool of videos drawn from the Internet. Raters of these videos were 15 heterosexual men, 17 nonheterosexual men, 19 heterosexual women, and 14 nonheterosexual women. Within each group ratings of the model's attractiveness were reliable (all Cronbach's $\alpha$ 's $\geq .92$ ) and the average ratings of these four groups were strongly correlated (all $p$ 's $<.0001$, all $r$ 's $\geq .87)$. Thus, these evaluations were averaged across all raters and the 12 male and 12 female models that were rated as the most sexually appealing were used for the study.

Twenty-five short videos showing animations of clouds that were of similar luminance as the sexual stimuli were used as neutral stimuli. The resolution of videos was 768 by 536 pixels, and videos were presented in full screen mode.

Pupil data. An SR Research Remote infrared gaze tracker recorded participants' pupil data. The program EyeLink computed pupil area as the number of the tracker's camera pixels occluded by the pupil. Pupil dilation was based on changes of pupil area when viewing sexual stimuli as compared to neutral stimuli.

Procedure. Participants provided written informed consent on arrival at the laboratory. They were seated in a dimly lit room facing a screen with resolution of 1024 
by 768 pixels. The gaze tracker was placed underneath the screen and collected data every millisecond with a $35 \mathrm{~mm}$ lens focused on participants' preferred eye. Participants' heads rested on a mount $500 \mathrm{~mm}$ from the lens. Participants watched an initial neutral stimulus followed, in random order, by presentations of sexual stimuli alternating with further neutral stimuli. After watching videos, participants completed a questionnaire including the aforementioned measures and received payment. The total procedure took approximately 30 minutes.

There is no consensus as to the most appropriate technique of analyzing pupil size data (Otero, Weekes, \& Hutton, 2011). We therefore decided on procedures that have previously yielded reliable pupil dilation data (Rieger \& Savin-Williams, 2012), and that were identical to procedures used for analyzing genital arousal responses (Chivers, Rieger, Latty, \& Bailey, 2004). For each participant, pupil data were averaged for each stimulus. Because pupils vary in size and degree of dilation, we computed $z$-scores of pupillary response within each participant. We then computed, for each participant, three average values reflecting pupil area to same-sex stimuli, other-sex stimuli, and neutral stimuli. As aforementioned, our measure of pupil dilation was based on changes of pupil area when viewing sexual stimuli as compared to neutral stimuli.

\section{Results}

Hypothesis 1. The first hypothesis is that bisexual men report elevated sexual curiosity compared with heterosexual men and homosexual men. We conducted a multiple regression analysis with the curvilinear term of sexual orientation predicting sexual curiosity. Results confirmed the hypothesis (Figure 1A). Bisexual men (Kinsey 2 
to 4) reported more sexual curiosity than heterosexual men (Kinsey 0 and 1) and homosexual men (Kinsey 5 and 6 ), $p<.0001, \beta=-.37$.

Hypothesis 2. The second hypothesis is that bisexual men are more aroused by both sexes compared with other men. Following previous reasoning (Rieger et al., 2005), we computed a variable representing each participant's response to his less-arousing (i.e., less dilation-triggering) sex. If bisexual men show bisexual arousal, they should dilate more to their less arousing sex (whichever sex this is) than either heterosexual or homosexual men. Thus, we expected a curvilinear effect of sexual orientation on participants' responses to their less arousing sex. Consistent with the second hypothesis, bisexual men dilated more to their less arousing sex than heterosexual or homosexual men, although the finding was not significant, $p=.10, \beta=-.10$ (Figure 1B).

Hypothesis 3. The third hypothesis states that bisexual men are more similar to homosexual than heterosexual men in their pupil dilation to the same sex versus the other sex. We computed a contrast score for pupil dilation with positive numbers indicating more dilation to the same sex, zero indicating equal dilation, and negative numbers indicating more dilation to the other sex. We then regressed this contrast score against the linear and curvilinear terms of sexual orientation. Figure 1C shows a linear effect suggesting that heterosexual men dilated more to the other sex, homosexual men dilated more to the same sex, and bisexual men had a dilation pattern between heterosexual and homosexual men, $p<.0001, \beta=.50$. Thus, in general, pupillary responses reflected selfreported sexual orientation. A non-significant curvilinear effect indicated that bisexual men did not dilate considerably more to the same sex than the other sex, $p=.23, \beta=-.07$. Hence, the third hypothesis was not confirmed. 
Hypotheses 4 and 5. Hypothesis 4 proposes that only bisexual men with elevated levels of sexual curiosity have bisexual arousal patterns, compared with other men. Alternatively, Hypothesis 5 proposes that some bisexual men have bisexual arousal, although not elevated levels of sexual curiosity, and that other bisexual men have high levels of sexual curiosity, although not bisexual arousal. These hypotheses were tested simultaneously by conducting multiple regression analyses and by computing how the interaction of sexual orientation with sexual curiosity related to pupillary responses.

Sexual curiosity interacted with the curvilinear term of sexual orientation, both for dilation to the less arousing sex and for dilation to the same sex versus the other sex, $p$ $=.04, \beta=-.24$, and $p=.01, \beta=.25$, respectively. Following statistical guidelines (Aiken $\&$ West, 1991), we examined these interactions at a higher level of sexual curiosity (1 SD above the mean, a score of 5.36) and at a lower level of sexual curiosity (1 $S D$ below the mean; a score of 2.94). At the higher level, bisexual men dilated significantly more to their less arousing sex compared with other men, $p=.009, \beta=-.24$ (Figure 1D). Furthermore, these bisexual men dilated equally to the same sex and other sex, yielding a linear effect of sexual orientation, $p<.0001, \beta=.48$ (Figure 1F).

At the lower level of sexual curiosity, bisexual men did not dilate significantly more to their less arousing sex, compared with other men, $p=.81, \beta=.02$ (Figure 1E). Moreover, they dilated more to the same sex than the other sex, yielding a curvilinear effect of sexual orientation, $p=.007, \beta=-.22$ (Figure 1G). In total, results confirmed the fourth hypothesis but not the alternative, fifth, hypothesis: Bisexual men with high sexual curiosity had bisexual arousal patterns, whereas bisexual men with lower sexual curiosity were primary aroused to the same sex, similar to homosexual men. 
Covariates. As aforementioned, bisexual men were older than other men and more likely recruited from sites where men seek sexual encounters. However, the interactions of sexual orientation with sexual curiosity were almost identical before and after controlling for these variables in multiple regression analyses. For dilation to the less arousing sex, the interaction remained similar, $p=04, \beta=-.24$, and $p=05, \beta=-.23$, respectively. For dilation to the same sex versus other sex, the interactions also remained similar, $p=.01, \beta=.25$, and $p=.02, \beta=.24$, respectively. Neither were these relations significantly moderated by age or recruitment venue (all $p$ 's $>.17$, all $\beta$ 's between -.08 and .11). Thus, age and recruitment venue were not the reasons for the reported differences between bisexual men with high and low levels of sexual curiosity and with bisexual or homosexual arousal patterns.

In total, results of Study 1 confirmed the hypothesis that level of sexual curiosity differentiates between bisexual men with bisexual arousal patterns and with homosexual arousal patterns. If these findings are robust, they should be replicable with other samples, and with different measures of sexual arousal. In Study 2 we examined this possibility with a sample of men whose genital arousal to sexual stimuli was assessed (Rosenthal et al., 2011). We tested the hypotheses as presented above, investigating whether bisexual men were more sexually curious than heterosexual and homosexual men, whether they showed greater sexual arousal to their less preferred sex, whether their arousal to men versus women was more similar to that of homosexual than heterosexual men, and how their sexual curiosity related to their sexual arousal.

\section{Study 2}

\section{Method}


Participants. All heterosexual, bisexual, and homosexual men were recruited through websites in the Chicago area where men seek sexual contacts with men, women, or both. Inclusion criteria required past sexual and romantic experiences with men or women, congruent with their identities as "straight," "bisexual," and "gay."

A total of 102 men participated in this study. Using previously applied methodology (Chivers et al., 2004; Rieger et al., 2005), 30 men were excluded who did not show a minimum genital response to any sexual stimuli (particularly, a minimum of $2 \mathrm{~mm}$ increase in penile circumference compared to neutral stimuli). The final 72 men reported sexual attractions "exclusively towards women" $(\mathrm{n}=16)$, "mostly towards women, but occasional attractions to men" $(\mathrm{n}=2)$, "mostly towards women but definite attractions towards men" $(\mathrm{n}=8)$, "towards both men and women" $(\mathrm{n}=6)$, "mostly towards men but definite attractions towards women" $(\mathrm{n}=10)$, "mostly towards men, but occasional attractions to women" $(\mathrm{n}=13)$, and "exclusively towards men" $(\mathrm{n}=17)$. The average age $(S D)$ was 34.41 (7.46) years. The most common ethnicity was Caucasian (64\%), followed by African-American (13\%); the remainder identified as Hispanic, Asian, and mixed ethnicities.

Among these sexual attraction groups there were no significant differences in proportions who were Caucasian, $\chi^{2}(6)=1.56, p=.95$. Men with exclusive sexual attractions towards women were younger than other men, $p=.02, R^{2}=.20$. Differences in age did not significantly affect results reported below.

\section{Measures.}

Sexual orientation. Sexual orientation was measured by two Kinsey-type scales (Kinsey et al., 1948) that were highly correlated $(p<.0001, r=.97)$ and averaged. For 
this composite average, a score of 0 indicated an exclusively heterosexual orientation, a score of 3 a bisexual orientation with equal attractions towards men and women, and a score of 6 an exclusively homosexual orientation.

In addition to these ratings, participants reported their sexual orientation identities; 16 indicated they were "straight," 29 were "bisexual," and 27 were "gay." These identities (converted into a numerical three-point scale) correlated strongly with the aforementioned sexual attraction average score, $p<.0001, r=.95$. Furthermore, all "straight men" had attraction scores of 0, all "bisexual men" had scores between 1 and 5, and for "gay men," 7 out of 27 had scores of 5, the remainder had scores of 5.5 or 6 . Thus, the aforementioned sexual attraction composite was a strong reflection of self-identity. Reported results were almost identical when the 3-point measure of identity rather than the Kinsey-typed composite score was used for analyses. For consistency with Study 1, and because the 7-point scale allowed more variability that a three-identity division, all reported results are based on the aforementioned composite average score.

Sexual curiosity. The scale described in Study 1 was used to assess sexual curiosity, which was a modification of a scale by Eysenck (Eysenck, 1970, 1973). Item reliability (Cronbach's $\alpha$ ) was .84 and responses were averaged within participants. For these averages, a score of 7 indicated maximum sexual curiosity.

Stimuli and penile circumference data. Several 3-minute videos were shown, including two male sexual stimuli (depicting two men having sex), two female sexual stimuli (depicting two women having sex), and neutral stimuli showing landscapes. Regarding the sexual stimuli, previous research suggests that for heterosexual men, a pure female sexual stimulus, depicting two women, tends to elicit more sexual arousal 
than a heterosexual stimulus, depicting a man and a woman; likewise, for homosexual men a pure male sexual stimulus, depicting two men, elicits more arousal than a heterosexual stimulus (Chivers et al., 2004; Chivers et al., 2007). Moreover, responses to heterosexual stimuli do not indicate whether arousal was to the male, the female, or both sexes, a question of particular importance for the present research. Hence, for the purpose of our study, pure male and pure female sexual stimuli were used.

An indium/gallium strain gauge measured changes in penile circumference, which were recorded with the BIOPAC MP100 data acquisition unit and the program AcqKnowledge.

Procedures. Participants provided written informed consent and then viewed the stimuli in a private room while wearing the penile strain gauge. Between two neutral stimuli, sexual stimuli were presented in random order. Between these stimuli, participants completed distraction tasks such as mentally alphabetizing words until they had returned to baseline (their genital response to neutral stimuli). Equivalent to Study 1, responses to stimuli were standardized within participants and three averages were created, one each for same-sex stimuli, other-sex stimuli, and neutral stimuli. Our index of genital arousal was based on changes of penile circumference when viewing sexual stimuli as compared to neutral stimuli.

For further detail on Study 2 methodology, please see previous publications based on this dataset (Rosenthal et al., 2011; Rosenthal et al., 2012).

\section{Results}

Hypothesis 1. We conducted multiple regression analyses mirroring those for Study 1. Consistent with the first hypothesis, compared with heterosexual men and 
homosexual men, bisexual men reported higher levels of sexual curiosity, $p=.05, \beta=-$ .26 (Figure 2A). Compared to Study 1 (Figure 1A) men in Study 2 scored generally higher in sexual curiosity; we discuss this difference below.

Hypothesis 2. Consistent with the second hypothesis, bisexual men had, on average, significantly greater genital responses to their less arousing sex than heterosexual and homosexual men, $p=.0002, \beta=-.45$ (Figure 2B).

Hypothesis 3. The third hypothesis involved whether bisexual men were similar to homosexual men in their sexual responses. Figure $2 \mathrm{C}$ shows a linear effect of sexual orientation; bisexual men were in-between heterosexual and homosexual men in their genital response to the same or the other sex, $p<.0001, \beta=.83$. Further, a curvilinear effect suggested that bisexual men were more aroused to the same sex than the other sex, similar to homosexual men, $p=.09, \beta=-.11$, although, this effect was not significant.

Hypotheses 4 and 5. We tested whether the above findings were moderated by level of sexual curiosity. Hypothesis 4 states that only bisexual men with elevated levels of sexual curiosity exhibit bisexual arousal, whereas those lower on sexual curiosity are aroused to one sex. Alternatively, Hypothesis 5 states that certain bisexual men have bisexual arousal patterns, although not elevated levels of sexual curiosity, and other bisexual men have high sexual curiosity, although not bisexual arousal.

Sexual curiosity interacted with the curvilinear term of sexual orientation for genital response to the less arousing sex and for response to the same sex versus the other sex, $p$ $=.07, \beta=-.32$, and $p=.007, \beta=.26$, respectively. At the higher level of sexual curiosity (1 $S D$ above the mean; a score of 6.26), bisexual men responded significantly more to their less arousing sex compared with other men, $p=.0008, \beta=-.53$ (Figure 2D). These 
bisexual men were equally aroused to the same sex and other sex, yielding a linear effect of sexual orientation, $p<.0001, \beta=.74$ (Figure 2F).

At the lower level of sexual curiosity (1 $S D$ below the mean; a score of 4.08), bisexual men did not respond significantly more to their less arousing sex compared with other men, $p=.43, \beta=-.12$ (Figure 2E). However, they responded more to the same sex than the other sex, yielding a curvilinear effect of sexual orientation, $p=.003, \beta=-.26$ (Figure 2G). As with Study 1, these results confirmed the fourth but not the fifth hypothesis: Bisexual men with high sexual curiosity exhibited bisexual genital arousal whereas those with lower levels of sexual curiosity were primarily genitally arousal by the same sex.

Covariates. Similar to Study 1, we examined whether the interactions of sexual orientation with sexual curiosity were affected by participants' age. For their genital response to the less arousing sex, the interaction was somewhat diminished after statistically controlling for age, $p=.07, \beta=-.32$, versus $p=.10, \beta=-.30$. For their genital response to the same sex versus other sex, the interactions were also somewhat diminished after controlling for age, $p=.007, \beta=.26$, and $p=.04, \beta=.21$. Yet, Sobel Tests indicated that these mediations were not significant, Sobel $t=1.23, S E=.01, p$ $=.22$, and Sobel $t=-1.43, S E=.01, p=.14$, respectively.

\section{Study 3}

Studies 1 and 2 suggest differences in degree of bisexual arousal, depending on sexual curiosity. However, given that our measure of sexual curiosity is a modified version of the original measure by Eysenck $(1970,1976)$, its validity needed to be 
established. Study 3 examined the correspondence of sexual curiosity with potentially related measures.

\section{Method}

Participants and Measures. A total of 83 men were recruited in a manner identical to Study 1. The average age $(S D)$ was $25.90(7.49)$ years.

Sexual orientation. Sexual orientation identities were measured as described in Study 1; 19 men indicated they were "straight," 9 were "mostly straight," 8 were "bisexual leaning straight," 4 were "bisexual," 8 were "bisexual leaning gay," 15 were "mostly gay," and 20 were "gay."

Sexual curiosity. The scale described in Study 1, a modification of a scale by Eysenck (Eysenck, 1970), was used to assess sexual curiosity. Item reliability (Cronbach's $\alpha$ ) was .89.

General curiosity. Two scales were used to measure general curiosity. The Curiosity and Exploration Inventory-II (CEI-II) assesses with 10 items the seeking of knowledge and new experiences and a willingness to embrace novelty (Kashdan et al., 2009). Example items are "I actively seek as much information as I can in new situations," and "Everywhere I go, I am out looking for new things or experiences." Item reliability (Cronbach's $\alpha$ ) was 89 .

The 10-item Curiosity/Interest in the World (C/IW) Scale from the 240-item VIA Inventory of Strengths (VIA Survey) assesses interest in a variety of subjects and the joy of exploration and discovery (Peterson \& Park, 2009; Peterson \& Seligman, 2004). Example items are "I can find something of interest in any situation," and "I really enjoy learning about other countries and cultures." Item reliability (Cronbach's $\alpha$ ) was .84. 
General sensation seeking. The 10-item Brief Sensation Seeking Scale assessed sensations from seeking novel and, at times, risky social and physical experiences (Hoyle et al., 2002). Example items are "I prefer friends who are excitingly unpredictable," and “I would like to try bungee jumping." Item reliability (Cronbach's $\alpha$ ) was .81.

Sexual sensation seeking. The pursuit of new and risky experiences in a sexual context was assessed with the 11-item Sexual Sensation Seeking Scale (Kalichman \& Rompa, 1995). Examples are "I like wild 'uninhibited' sexual encounters," and "I am interested in trying out new sexual experiences." Item reliability (Cronbach's $\alpha$ ) was .81.

For all measures, an average score of 7 (averaged within participants) indicated maximum endorsement.

Procedures. Participants were sent an online link to the survey. On the first page they provided written informed consent. Participants received no monetary compensation; hence, in order to maintain interest, the survey was created to be as brief as possible. It took between 5 and 10 minutes to complete.

\section{Results}

Hypothesis 6. We hypothesized that sexual curiosity corresponds with overall curiosity, overall sensation seeking, and sexual sensation seeking. Table 2 shows that all measures were significantly correlated. Sexual curiosity correlated modestly to the two measures of overall curiosity, the CEI-II and C/IW, $p=.004, r=.32$, and $p=.003, r$ $=.33$, respectively. General sensation seeking correlated with sexual sensation seeking in a similar fashion, $p=.001, r=.36$. Sexual curiosity related strongly to sexual sensation seeking, $p<.0001, r=.72$. Similarly, general curiosity measures showed modest to strong correlations with measures of general sensation seeking, $p<.0001, r=.74$, and $p$ 
$=.002, r=.33$. These results supported the proposal that sexual curiosity is not independent of overall curiosity, and that those with high levels of sexual curiosity also score high on theoretically related traits.

Other results. Similar to results found in Study 1 and Study 2, bisexual men scored higher on sexual curiosity than heterosexual men or homosexual men, $p=.008, \beta=-.30$. Figure $3 \mathrm{~A}$ shows that the general pattern is more comparable to the pattern found in Study 1 (Figure 1A) than in Study 2 (Figure 2A). The only other measure for which this curvilinear effect was significant was sexual sensation seeking, with bisexual men scoring higher on this trait than either heterosexual or homosexual men (Figure 3B), $p$ $=.01, \beta=-.29$.

\section{General Discussion}

Findings suggest, across two studies with different measures of sexual arousal, that men with bisexual identities exhibit at least two arousal patterns. For one group, sexual identity was reflected in their sexual arousal patterns, whereas the second group had arousal patterns similar to homosexual men. The difference between these groups related to their level of sexual curiosity: Those whose sexual identity matched their arousal patterns were also more sexually curious. The final study indicates that our measure of sexual curiosity is likely a valid measure.

\section{High Sexual Curiosity and Bisexual Arousal}

Some bisexual men were sexually aroused to both men and women, but this was true only for those who expressed relatively high levels of sexual curiosity. By contrast, sexual arousal patterns of heterosexual and homosexual men were little affected by their 
level of sexual curiosity (e.g., Figures 1F \& 1G), which was, on average, lower than the curiosity level of bisexual men.

Building on Eysenck's (1976) theory, we propose that genetic influences account for both the elevated level of sexual curiosity and bisexual arousal in this group of bisexual men. There is indirect evidence consistent with this hypothesis. Genotypes related to dopamine signaling predict personality characteristics such as sensation seeking and risk-taking (Lobo et al., 2010) and a wide range of novelty-seeking traits (Munafò et al., 2008). Dopamine-related genotypes also predict a variety of sexual characteristics, including promiscuity (Garcia et al., 2010), number of sex partners (Halpern et al., 2007) and sexual arousal (Ben Zion et al., 2006). Specific forms of dopamine receptor genes, related to sensation seeking, appear to be common in men with bisexual experiences (Hamer \& Copeland, 1994). Perhaps, then, dopamine-related genotypes predict the cooccurrence of sexual curiosity and bisexual arousal in certain men. Emerging methodologies allow assessing these associations, for example, by comparing DNA samples from mouthwashes of heterosexual, homosexual, and bisexual men, and by linking these genetic samples to level of sexual curiosity and physiological sexual arousal. Mechanisms other than common genetic factors should also be considered. Elevated curiosity includes an aroused state that motivates exploratory and reward-seeking behavior (Berlyne, 1960; Litman, 2005). Likewise, sexual behavior is based on sexual arousal, exploring opportunities, and reward-seeking (Pfaus et al., 2012). Furthermore, men can misattribute their arousal to a different source, at least temporarily (Hoffmann, 2012). For example, they can misattribute residual arousal from physical exercise to sexual stimuli and therefore experience enhanced sexual arousal to these stimuli (Cantor, 
Zillmann, \& Bryant, 1975). In theory, men who are already aroused because of elevated curiosity could reattribute this arousal to sexual stimuli depicting either sex, thus increasing their sexual arousal and rewarding experiences associated with both men and women.

Further research should examine what cues relate to sexual curiosity and bisexual arousal. Certain sexual preferences involve cues such as context, nonsexual body parts, behavior, or dress. In some cases these preferences are so strong that they are identified as paraphilias, or unusual and intense erotic attractions (Cantor, Blanchard, \& Barbaree, 2009). Paraphilic preferences are unlikely due to the same developmental factors as sexual attraction towards adults of the same sex or other sex (Cantor, 2012).

To date, there is no systematic evidence for the hypothesis that the co-occurrence of elevated sexual curiosity and bisexual arousal is part of a paraphilia. However, there is anecdotal evidence that some men who show bisexual arousal are likely to have paraphilic preferences and that they also score high on sexual curiosity (Cantor, 2010). Perhaps, in a man with elevated sexual curiosity, potential partners of either sex with his preferred sexual characteristics trigger his sexual arousal. Related to this hypothesis, for a proportion of bisexual individuals the gender of a potential partner is not relevant (Rust, 2002), leaving the possibility that other features trigger their sexual attraction and sexual arousal.

In addition, sexual interests in men and women can be expressed in ways other than in genital responses or pupil dilations. A recent study indicated that unlike for heterosexual or homosexual participants, bisexual participants were more likely to spend time viewing attractive images of both men and women (Lippa, 2013). It is possible, 
therefore, that bisexual men high in sexual curiosity spend the most time viewing these images. If this hypothesis were confirmed, it would add to the present findings that differences between men who identify as bisexual can be assessed with multiple measures.

\section{Low Sexual Curiosity and Homosexual Arousal}

For bisexual men who did not report high levels of sexual curiosity, we found no evidence of a bisexual response pattern. Rather, their sexual responses were, on average, similar to those of homosexual men (e.g., Figures 1D \& 1F). Perhaps these men identified as bisexual for reasons other than their pattern of sexual arousal. For example, sexual identity can also be derived from reflecting on past sexual experiences or from conforming to norms within particular social groups (Andersen, Cyranowski, \& Espindle, 1999).

It is further possible that these bisexual men are in a transitional stage from a bisexual identity to a homosexual identity. In fact, a number of bisexual men go through such transitions (Savin-Williams, Joyner, \& Rieger, 2012; Stokes, Damon, \& McKirnan, 1997). Hence, present sexual arousal patterns could be a predictor of their future sexual identities. If a transitional stage takes time, one possibility is that bisexual men who make these transitions to a homosexual identity (and therefore show homosexual arousal patterns) are younger than bisexual men with bisexual arousal patterns. The present studies, however, found no support for this hypothesis. Differences in arousal patterns were not substantially related to age.

Another possibility is that, rather than age, the number of sexual experiences with men and women is a predictor of future identity. For example, bisexual men with a 
homosexual arousal pattern might, at present, prefer sexual experiences with men over experiences with women, and this could affect the formation of their future identity. Hence, the assessment of temporal patterns of sexual experiences with both sexes, in addition to measures of sexual curiosity, could be informative.

Bisexual men who differ in sexual arousal patterns might also vary in other ways. A major personality trait that has been linked to sexual orientation is masculinity-femininity. Bisexual men are either in-between heterosexual and homosexual men in their masculinity-femininity (Cohen, 2002; Lippa, 2005) or, on some measures, more feminine than masculine, similar to homosexual men (Lippa, 2008). These findings correspond with the present results that certain bisexual men had bisexual arousal patterns while others had homosexual arousal patterns. Perhaps more feminine bisexual men also have sexual arousal patterns similar to homosexual men.

\section{Differences between Studies}

There are many similarities in findings among the three studies. One notable difference, however, was in level of sexual curiosity. A comparison of Figures 1A, 2A, and $3 \mathrm{~A}$ shows that on average men of all sexual orientations scored higher in sexual curiosity in Study 2 than Study 1 or Study 3. Study 2 inclusion criteria required that participants have had sexual experiences (Study 1 and Study 3 did not require this), and all of them (and not just some of them, as in Study 1 and Study 3) were recruited via websites where men sought sexual encounters. Men in Study 2 also had to be willing to have their genital arousal measured. Even among participants willing to participate in sexuality research, most are uninterested in participating in studies involving the assessment of their genital responses (Strassberg \& Lowe, 1995). Hence, such assessment 
could be an experience likely to appeal more to those who are more sexually adventurous. Any of these factors could have contributed to men in Study 2 being more sexually curious. Regardless of this difference, though, the associations of sexual curiosity with a bisexual orientation and bisexual arousal were similar across studies.

\section{Correspondence between Measures}

The present research describes patterns of sexual arousal based on a trait labeled sexual curiosity, assuming that it is an aspect of general curiosity. Table 2 indicates that there were indeed modest correlations of sexual curiosity with measures of overall curiosity. These correlations were within the range that might be expected given previous correlations of curiosity with theoretically relevant traits (Litman \& Silvia, 2006). The magnitude of the effect was also comparable to the effect found for sexual sensation seeking and general sensation seeking. This could indicate that for either trait (curiosity or sensation seeking) a modest component involves sexual interests.

Sexual curiosity strongly corresponded with sexual sensation seeking, which we interpreted as a sign of its validity. In fact, this correlation was one of the strongest found in the present studies, $p<.0001, r=.72$. Consequently, bisexual men scored higher on sexual sensation seeking than other men (Figure 3). On the other hand, conceptually, curiosity and sensation seeking are related but not identical traits (Collins et al., 2004; Litman \& Spielberger, 2003). Hence, it may be that our results should be interpreted with respect to sensation seeking rather than curiosity. We note, though, that at least one of our measures of general curiosity corresponded strongly with general sensation seeking, $p$ $<.0001, r=.74$. Thus, it is also possible that in our sample overall curiosity and overall 
sensation seeking were indeed part of the same underlying core trait, and this similarity was reflected in sexual curiosity and sexual sensation seeking.

Other research on curiosity has investigated different facets of the overall trait (Kashdan et al., 2009; Litman \& Silvia, 2006). Some facets of general curiosity may relate more strongly to sexual curiosity than others. The present research focused on the interplay of sexual curiosity with sexual arousal - and the possibility that differences in this characteristic distinguishes groups. Future research might address which facets of global curiosity are linked to, if not responsible for, the relationship of sexual curiosity with bisexual arousal.

\section{Conclusions}

Fewer men identify as bisexual than either heterosexual or homosexual (Laumann, Gagnon, Michael, \& Michaels, 1994; Savin-Williams et al., 2012) and, given past and present findings, only some of these appear to show bisexual arousal. Those who have such arousal patterns have a distinct personality characteristic - elevated sexual curiosity. Hence, the etiology of a strong bisexual arousal pattern in men might be different from the development of the more frequent sexual arousal towards only one sex. Regardless of the underlying developmental mechanisms, the present findings are in line with the notion that a male bisexual identity can be found in a diverse range of men who differ in sexual attitudes and feelings (Taywaditep \& Stokes, 1998). 


\section{References}

Aiken, L. S., \& West, S. G. (1991). Multiple regression: Testing and interpreting interactions. Thousand Oaks, CA: Sage Publications.

Andersen, B. L., Cyranowski, J. M., \& Espindle, D. (1999). Men's sexual selfschema. Journal of Personality and Social Psychology, 76, 645-661. doi: 10.1037/00223514.76.4.645

Bailey, J. M. (2009). What is sexual orientation and do women have one? In D. A. Hope (Ed.), Contemporary perspectives on lesbian, gay, and bisexual identities (Vol. 54, pp. 43-63). New York, NY: Springer.

Bailey, J. M., Rieger, G., \& Rosenthal, A. (2011). Still in search of bisexual sexual arousal: Comment on Cerny and Janssen (2011). Archives of Sexual Behavior, 40, 12931295. doi: $10.1007 / \mathrm{s} 10508-011-9778-5$

Bancroft, J., Graham, C. A., Janssen, E., \& Sanders, S. A. (2009). The dual control model: Current status and future directions. Journal of Sex Research, 46, 121-142. doi: $10.1080 / 00224490902747222$

Ben Zion, I. Z., Tessler, R., Cohen, L., Lerer, E., Raz, Y., Bachner-Melman, R., et al. (2006). Polymorphisms in the dopamine D4 receptor gene (DRD4) contribute to individual differences in human sexual behavior: desire, arousal and sexual function. Molecular Psychiatry, 11, 782-786. doi: 10.1038/sj.mp.4001832

Berlyne, D. E. (1960). Conflict, arousal, and curiosity. New York, NY: McGrawHill. 
Bradley, M. M., Miccoli, L., Escrig, M. A., \& Lang, P. J. (2008). The pupil as a measure of emotional arousal and autonomic activation. Psychophysiology, 45, 602-607. doi: 10.1111/j.1469-8986.2008.00654.x

Cantor, J. M. (2010). Is sexual orientation a paraphilia? Paper presented at the International Behavioral Development Symposium, Lethbridge, Canada.

Cantor, J. M. (2012). Is homosexuality a paraphilia? The evidence for and against. Archives of Sexual Behavior, 41, 237-247. doi: 10.1007/s10508-012-9900-3

Cantor, J. M., Blanchard, R., \& Barbaree, H. (2009). Sexual disorders. In P. H. Blaney \& T. Millon (Eds.), Oxford textbook of psychopathology (2nd ed., pp. 527-548). New York, NY: Oxford University Press.

Cantor, J. R., Zillmann, D., \& Bryant, J. (1975). Enhancement of experienced sexual arousal in response to erotic stimuli through misattribution of unrelated residual excitation. Journal of Personality and Social Psychology, 32, 69-75. doi: $10.1037 / \mathrm{h} 0076784$

Cerny, J., \& Janssen, E. (2011). Patterns of sexual arousal in homosexual, bisexual, and heterosexual men. Archives of Sexual Behavior, 40, 687-697-697. doi: $10.1007 / \mathrm{s} 10508-011-9746-0$

Chivers, M. L., Rieger, G., Latty, E. M., \& Bailey, J. M. (2004). A sex difference in the specificity of sexual arousal. Psychological Science, 15, 736-744. doi: 10.1111/j.0956-7976.2004.00750.x

Chivers, M. L., Seto, M. C., \& Blanchard, R. (2007). Gender and sexual orientation differences in sexual response to sexual activities versus gender of actors in sexual films. 
Journal of Personality and Social Psychology, 93, 1108-1121. doi: 10.1037/0022-

3514.93.6.1108

Cohen, K. M. (2002). Relationships among childhood sex-atypical behavior, spatial ability, handedness, and sexual orientation in men. Archives of Sexual Behavior, 31, 129143. doi: 10.1023/a:1014043504661

Collins, R. P., Litman, J. A., \& Spielberger, C. D. (2004). The measurement of perceptual curiosity. Personality and Individual Differences, 36, 1127-1141. doi: $10.1016 / \mathrm{S} 0191-8869(03) 00205-8$

Dodge, B., Schnarrs, P. W., Reece, M., Martinez, O., Goncalves, G., Malebranche, D., et al. (2012). Individual and social factors related to mental health concerns among bisexual men in the Midwestern United States. Journal of Bisexuality, 12, 223-245. doi: $10.1080 / 15299716.2012 .674862$

Eysenck, H. J. (1970). Personality and attitudes to sex: A factorial study. Personality: An International Journal, 1, 355-376.

Eysenck, H. J. (1973). Personality and attitudes to sex in criminals. Journal of Sex Research, 9, 295-306.

Eysenck, H. J. (1976). Sex and personality. Austin, TX: University of Texas Press.

Fox, R. C. (2003). Bisexual identities. In L. D. Garnets \& D. C. Kimmel (Eds.), Psychological perspectives on lesbian, gay, and bisexual experiences (2nd ed., pp. 86129). New York, NY: Columbia University Press.

Freund, K., Langevin, R., Cibiri, S., \& Zajac, Y. (1973). Heterosexual aversion in homosexual males. British Journal of Psychiatry, 122, 163-169. doi:

10.1192/bjp.122.2.163 
Garcia, J. R., MacKillop, J., Aller, E. L., Merriwether, A. M., Wilson, D. S., \& Lum, J. K. (2010). Associations between dopamine D4 receptor gene variation with both infidelity and sexual promiscuity. PLoS ONE, 5, e14162. doi:

10.1371/journal.pone.0014162

Goldinger, S. D., \& Papesh, M. H. (2012). Pupil dilation reflects the creation and retrieval of memories. Current Directions in Psychological Science, 21, 90-95. doi:

\section{$10.1177 / 0963721412436811$}

Halpern, C. T., Kaestle, C. E., Guo, G., \& Hallfors, D. D. (2007). Geneenvironment contributions to young adult sexual partnering. Archives of Sexual Behavior, 36, 543-554. doi: 10.1007/s10508-006-9084-9

Hamer, D. H., \& Copeland, P. (1994). The science of desire: The search for the gay gene and the biology of behavior. New York: Simon \& Schuster.

Heaven, P. C. L., Fitzpatrick, J., Craig, F. L., Kelly, P., \& Sebar, G. (2000). Five personality factors and sex: preliminary findings. Personality and Individual Differences, 28, 1133-1141. doi: 10.1016/S0191-8869(99)00163-4

Heaver, B., \& Hutton, S. B. (2011). Keeping an eye on the truth? Pupil size changes associated with recognition memory. Memory, 19, 398-405. doi:

$10.1080 / 09658211.2011 .575788$

Hess, E. H., \& Polt, J. M. (1960). Pupil size as related to interest value of visual stimuli. Science, 132, 349-350. doi: 10.2307/1706082

Hess, E. H., Seltzer, A. L., \& Shlien, J. M. (1965). Pupil response of hetero- and homosexual males to pictures of men and women: A pilot study. Journal of Abnormal Psychology, 70, 165-168. doi: 10.1037/h0021978 
Hoffmann, H. (2012). Considering the role of conditioning in sexual orientation. Archives of Sexual Behavior, 41, 63-71. doi: 10.1007/s10508-012-9915-9

Hoyle, R. H., Stephenson, M. T., Palmgreen, P., Lorch, E. P., \& Donohew, R. L. (2002). Reliability and validity of a brief measure of sensation seeking. Personality and Individual Differences, 32, 401-414. doi: 10.1016/S0191-8869(01)00032-0

Israel, T., \& Mohr, J. J. (2004). Attitudes towards bisexual women and men: Current research, future directions. Journal of Bisexuality, 4, 117-134. doi: 10.1300/J159v04n01_09

Janssen, E. (2002). Psychophysiological measurement of sexual arousal. In M. W. Wiederman \& B. E. Whitley, Jr (Eds.), Handbook for conducting research on human sexuality (pp. 139 -171). Mahwah N J: L. Erlbaum.

Janssen, E. (2011). Sexual arousal in men: A review and conceptual analysis. Hormones and Behavior, 59, 708-716. doi: doi: 10.1016/j.yhbeh.2011.03.004

Janssen, E., Vorst, H., Finn, P., \& Bancroft, J. (2002). The Sexual Inhibition (SIS) and Sexual Excitation (SES) Scales: II. Predicting psychophysiological response patterns. Journal of Sex Research, 39, 127-132. doi: 10.1080/00224490209552131

Kalichman, S. C., Johnson, J. R., Adair, V., Rompa, D., Multhauf, K., \& Kelly, J. A. (1994). Sexual sensation seeking: Scale development and predicting AIDS-risk behavior among homosexually active men. Journal of Personality Assessment, 62, 385-397. doi: 10.1207/s15327752jpa6203_1

Kalichman, S. C., \& Rompa, D. (1995). Sexual sensation seeking and sexual compulsivity scales: Reliability, validity, and predicting HIV risk behavior. Journal of Personality Assessment, 65, 586-601. doi: 10.1207/s15327752jpa6503_16 
Kashdan, T. B., Gallagher, M. W., Silvia, P. J., Winterstein, B. P., Breen, W. E., Terhar, D., et al. (2009). The curiosity and exploration inventory-II: Development, factor structure, and psychometrics. Journal Of Research In Personality, 43, 987-998. doi: 10.1016/j.jrp.2009.04.011

Kinsey, A. C., Pomeroy, W. B., \& Martin, C. E. (1948). Sexual behavior in the human male. Philadelphia: Saunders.

Laeng, B., Sirois, S., \& Gredebäck, G. (2012). Pupillometry. Perspectives on Psychological Science, 7, 18-27. doi: 10.1177/1745691611427305

Laumann, E. O., Gagnon, J. H., Michael, R. T., \& Michaels, S. (1994). The social organization of sexuality: Sexual practices in the United States. Chicago, IL: University of Chicago Press.

Lewis, R. J., Derlega, V. J., Brown, D., Rose, S., \& Henson, J. M. (2009). Sexual minority stress, depressive symptoms, and sexual orientation conflict: Focus on the experiences of bisexuals. Journal of Social and Clinical Psychology, 28, 971-992. doi: $10.1521 /$ jscp.2009.28.8.971

Lippa, R. (2013). Men and women with bisexual identities show bisexual patterns of sexual attraction to male and female "swimsuit models". Archives of Sexual Behavior, 42, 187-196. doi: 10.1007/s10508-012-9981-z

Lippa, R. A. (2005). Sexual orientation and personality. Annual Review of Sex Research, 16, 119-153.

Lippa, R. A. (2006). Is high sex drive associated with increased sexual attraction to both sexes? Psychological Science, 17, 46-52. doi: 10.1111/j.1467-9280.2005.01663.x 
Lippa, R. A. (2007). The relation between sex drive and sexual attraction to men and women: A Cross-national study of heterosexual, bisexual, and homosexual men and women. Archives of Sexual Behavior, 36, 209-222. doi: 10.1007/s10508-006-9146-z

Lippa, R. A. (2008). Sex differences and sexual orientation differences in personality: Findings from the BBC Internet survey. Archives of Sexual Behavior, 37, 173-187. doi: 10.1007/s10508-007-9267-z

Litman, J. (2005). Curiosity and the pleasures of learning: Wanting and liking new information. Cognition \& Emotion, 19, 793-814. doi: 10.1080/02699930541000101

Litman, J. A., \& Silvia, P. J. (2006). The latent structure of trait curiosity: Evidence for interest and deprivation curiosity dimensions. Journal of Personality Assessment, 86, 318-328. doi: 10.1207/s15327752jpa8603_07

Litman, J. A., \& Spielberger, C. D. (2003). Measuring epistemic curiosity and its diversive and specific components. Journal of Personality Assessment, 80, 75-86. doi: 10.1207/s15327752jpa8001_16

Lobo, D. S. S., Souza, R. P., Tong, R. P., Casey, D. M., Hodgins, D. C., Smith, G. J., et al. (2010). Association of functional variants in the dopamine D2-like receptors with risk for gambling behaviour in healthy Caucasian subjects. Biological Psychology, 85, 33-37. doi: 10.1016/j.biopsycho.2010.04.008

Munafò, M. R., Yalcin, B., Willis-Owen, S. A., \& Flint, J. (2008). Association of the dopamine D4 receptor (DRD4) gene and approach-related personality traits: Metaanalysis and new data. Biological Psychiatry, 63, 197-206. doi:

10.1016/j.biopsych.2007.04.006 
Otero, S. C., Weekes, B. S., \& Hutton, S. B. (2011). Pupil size changes during recognition memory. Psychophysiology, 48, 1346-1353. doi: 10.1111/j.14698986.2011.01217.x

Peterson, C., \& Park, N. (2009). Classifying and measuring strengths of character. In S. J. Lopez \& C. R. Snyder (Eds.), Oxford library of psychology (2nd ed., pp. 25-33). New York, NY: Oxford University Press.

Peterson, C., \& Seligman, M. E. P. (2004). Character strengths and virtues: A handbook and classification. Washington, DC and New York, NY: American Psychological Association and Oxford University Press.

Pfaus, J., Kippin, T., Coria-Avila, G., Gelez, H. 1. n., Afonso, V., Ismail, N., et al. (2012). Who, what, where, when (and maybe even why)? How the experience of sexual reward connects sexual desire, preference, and performance. Archives of Sexual Behavior, 41, 31-62. doi: 10.1007/s10508-012-9935-5

Quist, M. C., Watkins, C. D., Smith, F. G., Little, A. C., DeBruine, L. M., \& Jones, B. C. (2012). Sociosexuality predicts women's preferences for symmetry in men's faces. Archives of Sexual Behavior, 41, 1415-1421. doi: 10.1007/s10508-011-9848-8

Rieger, G., Chivers, M. L., \& Bailey, J. M. (2005). Sexual arousal patterns of bisexual men. Psychological Science, 16, 579-584. doi: 10.1111/j.14679280.2005.01578.x

Rieger, G., \& Savin-Williams, R. C. (2012). The eyes have it: Sex and sexual orientation differences in pupil dilation patterns. PLOS ONE, 7, e40256. doi: 10.1371/journal.pone.0040256 
Rieger, G., Stief, M., Puts, D. A., \& Savin-Williams, R. C. (2012). Two routes to bisexuality: Personality and sexual arousal. Paper presented at the Human Behavior and Evolution Society, Albuquerque, NM.

Rosenthal, A. M., Sylva, D., Safron, A., \& Bailey, J. M. (2011). Sexual arousal patterns of bisexual men revisited. Biological Psychology, 8, 112-115. doi:

10.1016/j.biopsycho.2011.06.015

Rosenthal, A. M., Sylva, D., Safron, A., \& Bailey, J. M. (2012). The male bisexuality debate revisited: Some bisexual men have bisexual arousal patterns. Archives of Sexual Behavior, 41, 135-147. doi: 10.1007/s10508-011-9881-7

Rust, P. C. (2001). Two many and not enough: The meanings of bisexual identities. Journal of Bisexuality, 1, 31-68. doi: 10.1300/J159v01n01_04

Rust, P. C. R. g. (2002). Bisexuality: The state of the union. Annual Review of Sex Research, 13, 180-240.

Sakheim, D. K., Barlow, D. H., Beck, J. G., \& Abrahamson, D. J. (1985). A comparison of male heterosexual and male homosexual patterns of sexual arousal. Journal of Sex Research, 21, 183-198. doi: 10.1080/00224498509551257

Savin-Williams, R. C., Joyner, K., \& Rieger, G. (2012). Prevalence and stability of self-reported sexual orientation identity during young adulthood. Archives of Sexual Behavior, 41, 103-110. doi: 10.1007/s10508-012-9913-y

Seto, M. C. (2004). Pedophilia and sexual offenses against children. Annual Review of Sex Research, 15, 321-361. 
Stokes, J. P., Damon, W., \& McKirnan, D. J. (1997). Predictors of movement toward homosexuality: A longitudinal study of bisexual men. Journal of Sex Research, 34, 304-312. doi: 10.1080/00224499709551896

Strassberg, D., \& Lowe, K. (1995). Volunteer bias in sexuality research. Archives of Sexual Behavior, 24, 369-382. doi: 10.1007/bf01541853

Taywaditep, K. J., \& Stokes, J. P. (1998). Male bisexualities: A cluster analysis of men with bisexual experience. Journal of Psychology \& Human Sexuality, 10, 15-41. doi: 10.1300/J056v10n01_02

ten Donkelaar, H. J., Němcová, V., Lammens, M., Overeem, S., \& Keyser, A. (2011). The Autonomic Nervous System. Clinical Neuroanatomy, doi: 10.1007/19781003-1642-19134-19133_19112.

Tollison, C. D., Adams, H. E., \& Tollison, J. W. (1979). Cognitive and physiological indices of sexual arousal in homosexual, bisexual, and heterosexual males. Journal of Behavioral Assessment, 1, 305-314. doi: 10.1007/BF01321372

Weinrich, J. D., \& Klein, F. (2002). Bi-gay, bi-straight, and bi-bi. Journal of Bisexuality, 2, 109-139. doi: 10.1300/J159v02n04_07

Zietsch, B. P., Verweij, K. J. H., Bailey, J. M., Wright, M. J., \& Martin, N. G. (2010). Genetic and environmental influences on risky sexual behaviour and its relationship with personality. Behavior Genetics, 40, 12-21. doi: 10.1007/s10519-0099300-1

Zivony, A. (2013). The invisible stereotypes of bisexual men. Archives of Sexual Behavior. 
Zuckerman, M. (1979). Sensation seeking: beyond the optimal level of arousal.

Hillsdale, N.J.: Erlbaum. 


\section{Appendix}

Scale Items: Sexual Curiosity Scale

"The thought of having a threesome is appealing to me."

"If I were invited to be in an orgy, I would accept."

"I believe in taking my sexual pleasures where I find them."

"The idea of partner-swapping is exciting to me."

"When it comes to my sexual preferences, I would do almost anything for a dare."

"If I were invited to see a porn movie, I would accept."

"Casual sex is appealing to me."

"I would enjoy watching my usual partner having sex with someone else."

"Sex without love is appealing to me."

"If I were offered a highly pornographic magazine, I would accept it." 
Table 1

Distribution of Sexual Orientation Identities across Ages, Ethnicities, and Recruitment Venues of 277 men.

\begin{tabular}{|c|c|c|c|c|c|c|c|}
\hline & \multicolumn{7}{|c|}{ Sexual Orientation Identity } \\
\hline & $\begin{array}{c}\text { Exclusively } \\
\text { Straight }\end{array}$ & $\begin{array}{l}\text { Mostly } \\
\text { Straight }\end{array}$ & $\begin{array}{c}\text { Bisexual Leaning } \\
\text { Straight }\end{array}$ & Bisexual & $\begin{array}{c}\text { Bisexual Leaning } \\
\text { Gay }\end{array}$ & Mostly Gay & $\begin{array}{c}\text { Exclusively } \\
\text { Gay }\end{array}$ \\
\hline Number & 56 & 38 & 25 & 15 & 36 & 53 & 54 \\
\hline Average Age $(S D)$ & $20.36(2.39)$ & $23.55(6.12)$ & $25.04(7.92)$ & $29.73(11.75)$ & $23.67(6.04)$ & $22.81(5.11)$ & $23.76(6.22)$ \\
\hline $\begin{array}{l}\text { Percentage }(n) \\
\text { Caucasian }\end{array}$ & $68(38)$ & $66(25)$ & $68(17)$ & $60(9)$ & $56(20)$ & $68(36)$ & 72 (39) \\
\hline $\begin{array}{l}\text { Percentage }(n) \text { from } \\
\text { Sexual Websites }\end{array}$ & $0(0)$ & $29(11)$ & $36(9)$ & $33(5)$ & $33(12)$ & $23(12)$ & $11(6)$ \\
\hline
\end{tabular}

Note. Caucasian was the most common ethnicity in men (66\%). The second most common group indicated mixed ethnicities (12\%), and the remainder identified as African-American, Hispanic, Asian, and Native-American. 
Table 2

Intercorrelations for Measures of Sexual Curiosity, General Curiosity, General Sensation Seeking, and Sexual Sensation Seeking of 83 men.

\begin{tabular}{|c|c|c|c|c|c|}
\hline Measure & Sexual Curiosity & $\begin{array}{c}\text { General Curiosity } \\
\text { (CEI-II) }\end{array}$ & $\begin{array}{c}\text { General Curiosity } \\
\text { (C/IW) }\end{array}$ & General Sensation Seeking & Sexual Sensation Seeking \\
\hline Sexual Curiosity & & $.32 *$ & $.33 *$ & $.24 *$ & $.72 * * *$ \\
\hline $\begin{array}{l}\text { General Curiosity } \\
\text { (CEI-II) }\end{array}$ & & & $.61 * * *$ & $.74 * * *$ & $.42 * * *$ \\
\hline $\begin{array}{l}\text { General Curiosity } \\
\text { (C/IW) }\end{array}$ & & & & $.33 *$ & $.33^{*}$ \\
\hline $\begin{array}{l}\text { General Sensation } \\
\text { Seeking }\end{array}$ & & & & & $.36^{* *}$ \\
\hline $\begin{array}{l}\text { Sexual Sensation } \\
\text { Seeking }\end{array}$ & & & & & \\
\hline
\end{tabular}

Note. $* p<.05, * * p<.001, * * * p<.0001$ 

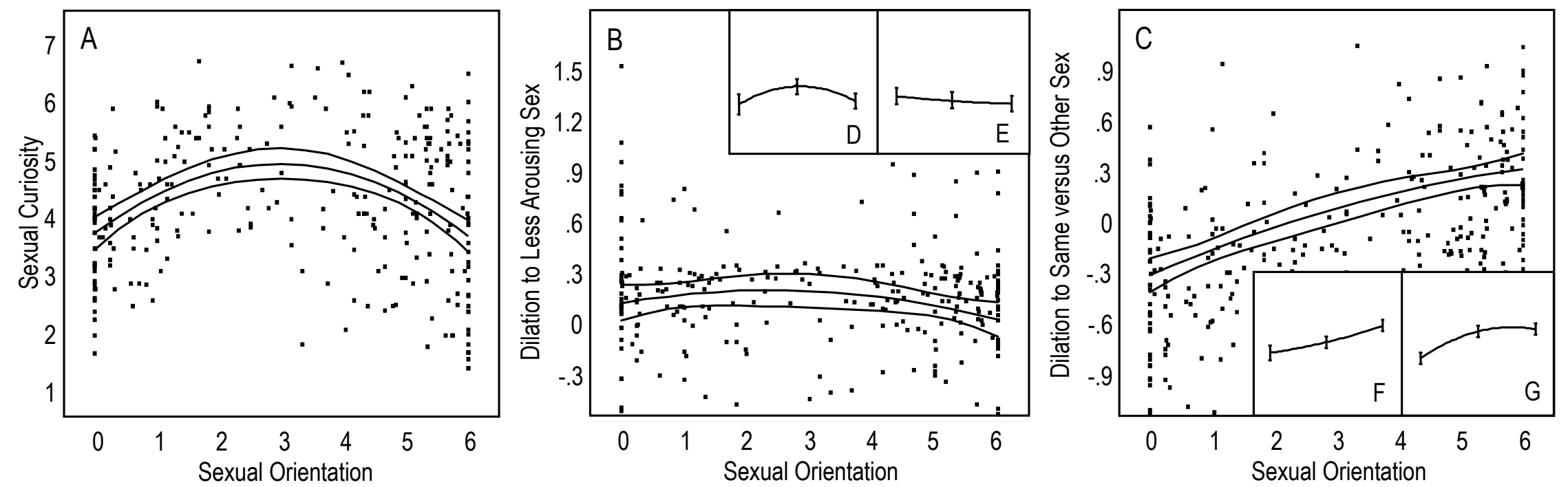

Figure 1. For 277 men, self-reported sexual orientation relates to self-reported sexual curiosity (A), pupil dilation to their less arousing sex (B), and pupil dilation to the same sex versus dilation to the other sex (C). Sexual curiosity interacts with sexual orientation, as shown for sexual curiosity scores $1 S D$ above the mean (D, F), and $1 S D$ below the mean (E, G). Pupil dilation scores are $z$-scores within participants. On the $\mathrm{X}$ axes, 0 represents an exclusive heterosexual orientation, 3 a bisexual orientation, and 6 an exclusive homosexual orientation. Lines represent regression coefficients with 95\% confidence intervals. Dots represent participants' average scores. 

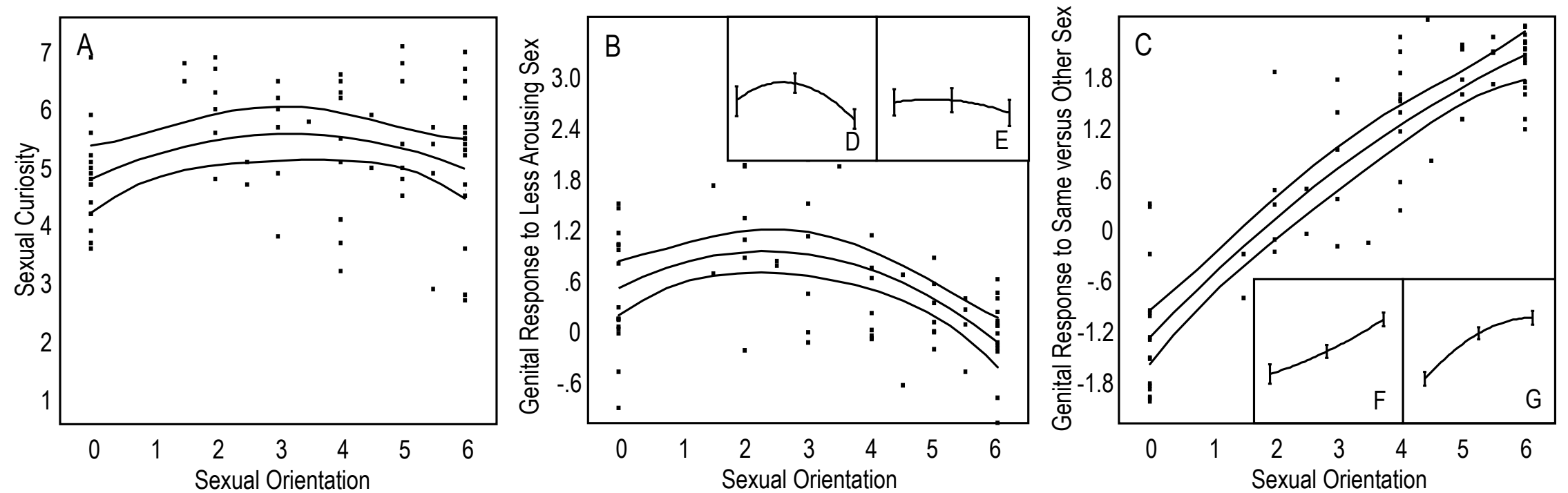

Figure 2. For 72 men, self-reported sexual orientation relates to self-reported sexual curiosity (A), genital response to their less arousing sex (B), and genital response to the same sex versus the other sex (C). Sexual curiosity interacts with sexual orientation, as shown for sexual curiosity scores $1 S D$ above the mean (D, F), and $1 S D$ below the mean (E, G). Genital response scores are $z$-scores within participants. On the $\mathrm{X}$ axes, 0 represents an exclusive heterosexual orientation, 3 a bisexual orientation, and 6 an exclusive homosexual orientation. Lines represent regression coefficients with 95\% confidence intervals. Dots represent participants' average scores. 

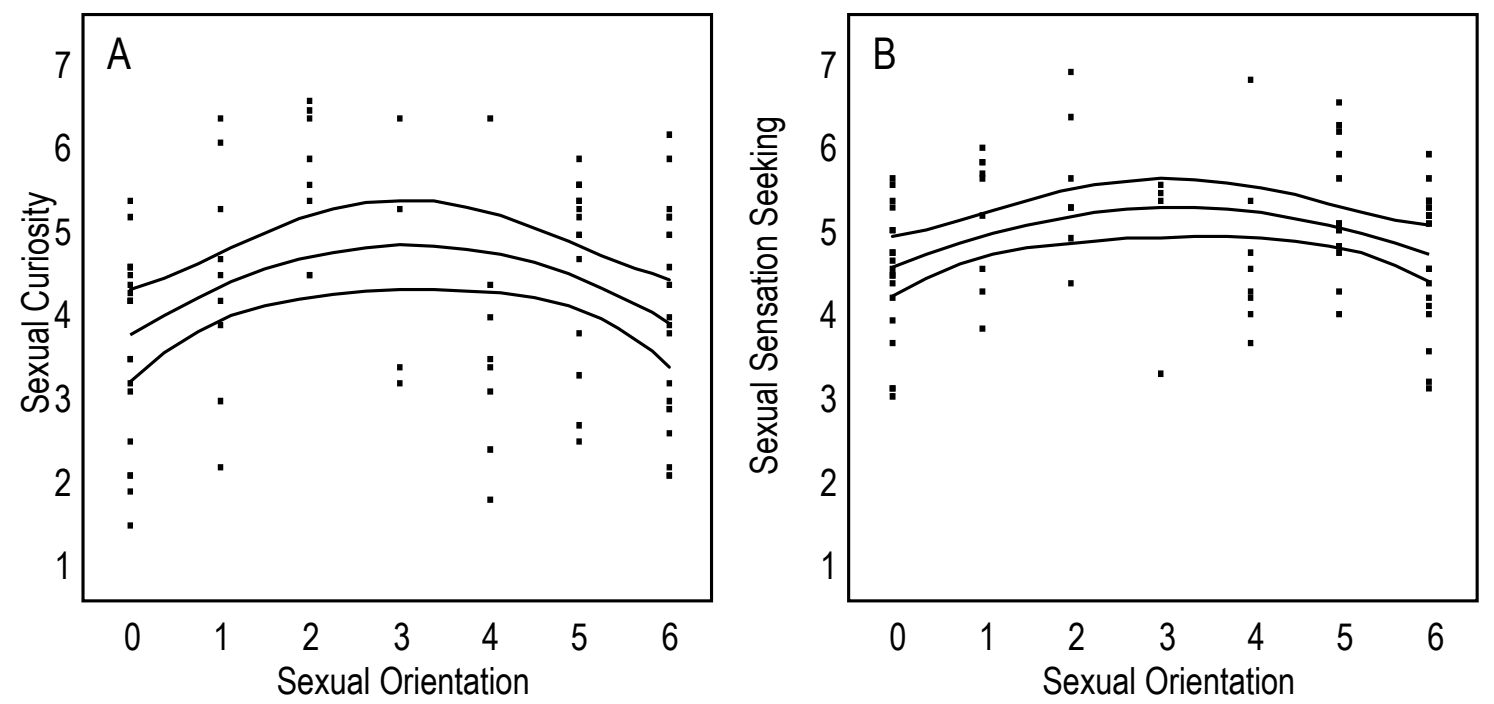

Figure 3. For 83 men, self-reported sexual orientation relates to self-reported sexual curiosity (A), and self-reported sexual sensation seeking (B). On the $\mathrm{X}$ axes, 0 represents an exclusive heterosexual orientation, 3 a bisexual orientation, and 6 an exclusive homosexual orientation. Lines represent regression coefficients with 95\% confidence intervals. Dots represent participants' average scores. 